Polymer Journal, Vo. 7, No. 3, pp 342-351 (1975)

\title{
Effect of Pressure on Melting Temperatures of Polyethylene Fractions
}

\author{
Kan'ichiro Takamizawa, Akio Ohno, and Yoshiko Urabe \\ Department of Applied Science, Faculty of Engineering, \\ Kyushu University, Fukuoka 812, Japan.
}

(Received September 30, 1974)

\begin{abstract}
Differential thermal analysis of polyethylene crystals was made at pressures up to $5 \mathrm{kbar}$. The crystals studied were fully extended chain crystals of two low molecular weight fractions, and a solution-grown crystal of a high molecular weight fraction. The melting curves of the former crystals were represented by the Simon equation. The latter crystal, having a lamellar thickness of $180 \AA$, showed reorganization during the heating process in the differential thermal analysis at $2.5 \mathrm{kbar}$ and above. In order to determine accurately its melting temperature at $5 \mathrm{kbar}$ a pressure annealing experiment was made. These results showed that the depression of the melting temperature of folded-chain crystals is considerably smaller, even at high pressures, than that reported previously. The slopes of the melting curves at atmospheric pressure are almost the same for all the crystals studied. This fact can be reasonably interpreted on the basis of a two-phase model.
\end{abstract}

KEY WORDS Polyethylene Fraction / Melting Temperature / High Pressure / Differential Thermal Analysis / Pressure Annealing / Slope of Melting Curve /

The crystallization of polyethylene from the melt under high pressure results in so-called extended-chain crystals. ${ }^{1-3}$ In order to study the formation and properties of such crystals, it is necessary to know accurately the effect of pressure on the melting temperature of polyethylene. In general, melting temperatures of polymers are dependent on their morphological nature, which is characterized usually by the thickness and interfacial structure of lamellar crystallites. The melting temperature-pressure relation, therefore, must be determined for samples of a given texture. Although a number of melting experiments for polyethylene under pressure have been reported, ${ }^{4-10}$ the only work carried out with this precise intention was that of Davidson and Wunderlich. ${ }^{10}$ They showed from differential thermal analysis (DTA) under pressure that the difference in melting temperature between extended- and folded-chain crystals of unfractionated polyethylene increased upon going to higher pressures. Their result has, however, some uncertainty because the effects of time-dependent factors in the thermal measure- ment on the melting temperatures are obscure. These factors include superheating, in the conventional usage of this concept, for extendedchain crystals and reorganization for foldedchain crystals of thin lamellar thickness.

Molecular weight homogeneity has been shown to play an important role in the sharpness of the melting process and thus the precise determination of the melting temperature. ${ }^{11,12}$ The high-pressure DTA apparatus developed by Takemura and coworkers ${ }^{13}$ has permitted such an experiment to be carried out using only a very small amount of sample, so that it has become possible to study molecular weight fractions. In order to reexamine the phase diagram for polyethylene, this report deals with the melting behavior under pressures up to $5 \mathrm{kbar}$ for fully extended chain crystals of two low molecular weight fractions and a folded-chain crystal prepared from dilute solutions of a high molecular weight fraction.

The melting curves for the former crystals were accurately determined because the superheating or reorganization had no influence on 
the determination of their melting temperatures. on the other hand, the folded-chain crystal of $180 \AA$ lamellar thickness melted without reorganization at least up to $2 \mathrm{kbar}$. Slopes of the melting curves at atmospheric pressure for these crystals have been discussed in terms of a twophase model composed of a central crystalline core and disordered surface layers.

\section{EXPERIMENTAL}

\section{DT A under High Pressure}

The DTA cell used in this investigation was that described by Takemura and coworkers ${ }^{13}$ with the exception that one thermocouple assembly was modified. A hand oil pump and an intensifier* were used to generate hydrostatic pressures up to about $10 \mathrm{kbar}$ in light mineral oil; the pressure was fed to the DTA cell and a container for a manganin coil gauge. The intensifier and the gauge vessel, together with a bridge box, were thermostated at about $35^{\circ} \mathrm{C}$. In this way temperature corrections for the manganin coils were avoided.

Figure 1 shows the thermocouple assembly of the DTA cell. A sheathed Chromel-Alumel thermocouple (Thermocoax, $1 \mathrm{~mm}$ outside di-

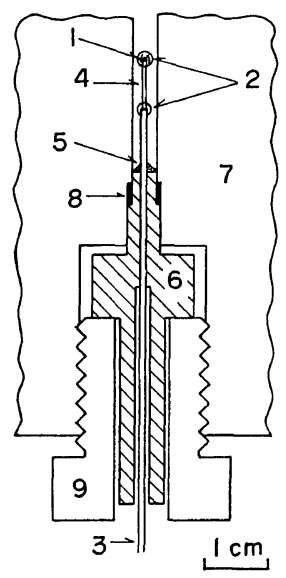

Figure 1. Drawing of thermocouple assembly of high pressure DTA: (1) sample; (2) epoxy resin; (3) sheathed thermocouple; (4) thermocouple wires;

(5) solder; (6) thermocouple plug; (7) heating block;

(8) copper packing; (9) threaded plug.

* We should like to thank Professor T. Takemura for lending us the intensifier. ameter) was used as an open type and soldered to a plug after being inserted to its bore. The bare portion of the thermocouple wires was $8 \mathrm{~mm}$ long. After being weighed, some pieces of a pressed sample of about $1 \mathrm{mg}$ were put on the hot junction and covered with epoxy resin to prevent them from contamination by the pressure-transmitting fluid. The junction of the reference thermocouple was surrounded only by the resin.

The DTA cell was heated by two sheathed heaters. The heating rate was controlled manually by adjusting the voltage supplied to the heaters. The normal heating rate was $6^{\circ} \mathrm{C} / \mathrm{min}$. Sample and differential temperatures were recorded as a function of time.

Each DTA thermocouple used was calibrated at least at two temperatures in the measuring range against a standard thermocouple. This was a sheathed thermocouple of insulated closetype, which had been calibrated on the basis of melting points of four pure substances and the boiling point of distilled water. The purity of both the tin and the indium used for the calibration was 99.999\%. The organic compounds used, benzoic acid and naphthalene, were purified by a zone-melting technique. The melting plateau was read on a recorder with a precision of 0.002 $\mathrm{mV}$.

DTA transition temperatures, in general, are defined by the temperature of the peak position or that of the intersection of the extrapolated slope of the low-temperature side of the peak with the base line. Our apparatus was calibrated by the measurement of melting of indium at ordinary pressure and of bismuth at high pressures. The intersection temperatures were found to be in better agreement with literature data than were the peak temperatures and on the average $0.5^{\circ} \mathrm{C}$ lower than the literature data regardless of sample size; the endothermic heats of the various samples ranged from 40 to 200 mcal. The literature data for bismuth were those recalculated by $\mathrm{Babb}^{14}$ from Bridgman's result $^{15}$ on the basis of the change of a fixed point of high pressure. The intersection temperatures, after being corrected by the value of $0.5^{\circ} \mathrm{C}$, were used as the melting temperatures of the polymer specimens. 


\section{Pressure Calibration and Measurement}

The manganin coil used had a resistance of about $120 \Omega$ and was seasoned to remove strain. ${ }^{16}$ The change of its resistance was read with precision of $0.05 \%$ by means of a modified d.c. bridge. The gauge was calibrated by utilizing the following relation for the solid-liquid transition of mercury: ${ }^{16}$

$$
P=38227\left[(T / 234.29)^{1.1772}-1\right]
$$

where $P$ is the pressure in bars and $T$ the melting point at $P$. The isobaric thermal analysis of mercury was carried out at a heating rate of about $0.1{ }^{\circ} \mathrm{C} / \mathrm{min}$ and the melting point was read from the melting plateau. The most probable value of the pressure coefficient of the coil resistance was determined to within a standard deviation of $0.1 \%$ from five measurements at different pressures below $7.6 \mathrm{kbar}$.

After the bridge had been balanced, its amplified output signal was recorded. One division deflection on the chart amounted to about 5 bar. An increase in pressure upon heating during a DTA run was followed and the pressure was taken at the moment melting started. The change during the melting was so small that it was not detectable.

\section{Annealing under High Pressure}

In annealing experiments under high pressure, a polymer specimen was immersed into silicone oil (10 c Stoke) in a sample cell, drawn schematically in Figure 2. The silicone oil was sealed off with mercury from the pressure trans-

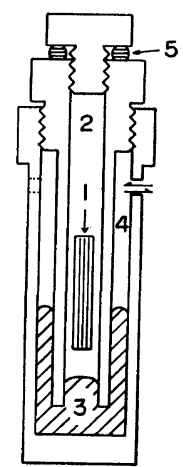

Figure 2. Schematic diagram of sample container used for high pressure annealing: (1) sample; (2) silicone oil; (3) mercury; (4) light mineral oil; (5) O-ring. mitting fluid (light mineral oil). Thus, it was possible to protect the specimen from contamination or dissolution by the mineral oil. The sample cell was placed in a pressure vessel of $12 \mathrm{~mm}$ inside and $80 \mathrm{~mm}$ outside diameter. The system was pressurized at room temperature to near an annealing pressure and then the vessel was heated to an annealing temperature in a silicone oil bath. During heating the pressure was adjusted to come to the desired pressure at the annealing temperature. After the temperature at the cavity of the vessel came to equilibrium with the bath temperature, which was controlled to within $\pm 0.2^{\circ} \mathrm{C}$ at $200^{\circ} \mathrm{C}$ and above, the specimen was maintained for $30 \mathrm{~min}$ at the annealing condition. Owing to the large heat capacity of the pressure vessel a period of about $2 \mathrm{hr}$ was required for the temperature equilibrium. After the annealing the vessel was cooled to room temperature under pressure in about $1.5 \mathrm{hr}$. The specimen was washed successively with benzene and acetone, dried in vacuo, and characterized.

\section{Materials and Their Characterizations}

Three narrow molecular weight fractions of linear polyethylene were used in this study. The fractions were prepared from Sholex-6050 (Showa Denko Co.) by repeated fractionations: precipitational and column fractionation. Two of them, having number-average molecular weights of 2230 and 3040, respectively, were used as fully extended chain crystals. The remaining one has a viscosity-average molecular weight of $4.5 \times 10^{4}$. These fractions are abbreviated as M2230, M3040, and M45000, respectively.

The number-average molecular weight was determined by means of IR absorption of the vinyl end group at $908 \mathrm{~cm}^{-1}$, on the assumption that one end of a Sholex-type polyethylene molecule has this group. ${ }^{17}$ The molar extinction coefficient of the band was calibrated by the use of 1-decene. A slight increase in the IR absorption of the carbonyl group at $1720 \mathrm{~cm}^{-1}$ was observed after repeated fractionation procedures. The correction for the number-average molecular weight was made on the assumption that the oxidation took place only on the vinyl end group, and amounted to about $5 \mathrm{~mol} \%$. The viscosity-average molecular weight was calculated 
from the intrinsic viscosity in decalin at $135^{\circ} \mathrm{C}$ according to Chiang's relation. ${ }^{18}$

The molecular weight distributions of these fractions were very sharp. For example, in the column fractionation by which M2230 was obtained its preceding and succeeding fractions were found to have the molecular weights of 2020 and 2300, respectively. The ratios of weight to number-average molecular weight were estimated to be in the range $1.01 \sim 1.02$. The method of this estimation ${ }^{19}$ will be described elsewhere.

M2230 and M3040 were crystallized from the melt, the former by slow cooling and the latter by isothermal crystallization at $122.0^{\circ} \mathrm{C}$ for 1,500 min. The folded-chain crystal was prepared from a $0.025 \%$ solution of M45000 in isoamyl acetate at $112.6^{\circ} \mathrm{C}$. After $45 \mathrm{hr}$, the solution was filtered at the crystallization temperature, and then the crystal was washed with hot solvent and dried in vacuo.

For all the specimens, the densities $\rho$ were determined at $30^{\circ} \mathrm{C}$ in a gradient column with toluene and chlorobenzene as media, and could be measured to $\pm 0.0005 \mathrm{~g} / \mathrm{cm}^{3}$. The crystallite thickness was determined from low-angle X-ray diffraction measurements using a Rigaku-Denki Type 2 camera. The well-defined maxima were converted to linear dimensions $L$ by means of Bragg's law. The heat of fusion $\Delta H^{*}$ was determined with a Perkin-Elmer DSC-1B calorimeter. The heating rate was $5^{\circ} \mathrm{C} / \mathrm{min}$ and sample weights were of the order of $3 \mathrm{mg}$. The heats of fusion were calculated by comparison with the fusion curve of a known weight of indium.

These characteristics of the specimens are listed in Table $I$, together with the average chain length 1 calculated from the molecular weights and the mass crystallinity $\alpha_{\mathrm{m}}$ obtained from the densities.

Table I. Characteristics of specimens

\begin{tabular}{lrrrrr}
\hline Fraction & $l, \AA$ & $L, \AA$ & $\begin{array}{c}\rho, \\
\mathrm{g} / \mathrm{cm}^{3}\end{array}$ & $\alpha_{\mathrm{m}}$ & $\begin{array}{l}\Delta H^{*}, \\
\mathrm{cal} / \mathrm{g}\end{array}$ \\
\hline M2230 & 202 & 223 & 0.979 & 0.889 & 57.2 \\
M3040 & 276 & 292 & 0.983 & 0.913 & 59.0 \\
M45000 & 4080 & 180 & 0.974 & 0.860 & 53.5 \\
\hline
\end{tabular}

\section{RESULTS AND DISCUSSION}

DTA and Melting Temperature of Fully Extended Chain Crystals of Low Molecular Weight Fractions under Pressure

M2230 and M3040 crystals can be defined as fully extended chain crystals, since Table I shows that the chain length corresponds to the crystallite thickness. The DTA curves of M3040 and bismuth at about $5 \mathrm{kbar}$ are compared in Figure 3. For convenience the abscissa is converted to a linear temperature scale. The sample size of bismuth was adjusted to give nearly the same peak area as that of M3040. As illustrated in Figure 3, the melting peaks of both fractions were very sharp and the melting temperatures (the intersection temperatures) could be determined accurately. Upon going to higher pressures the peak area decreased whereas the difference in temperature between the intersection and peak, as well as the peak width, was almost constant. Changing the heating rate from 6 to $1^{\circ} \mathrm{C} / \mathrm{min}$ had no influence on the melting temperature. In general, thin lamellar crystals of the low molecular weight extended chain type did not show any superheating in the atmospheric melting process. ${ }^{20,21}$ From this and the experimental facts described above, the superheating effect is considered to be absent even at high pressures.

The experimental data are listed in Table II, and plotted in Figure 4. The melting temperature at atmospheric pressure is the average of several determinations. The data were fitted to the Simon equation

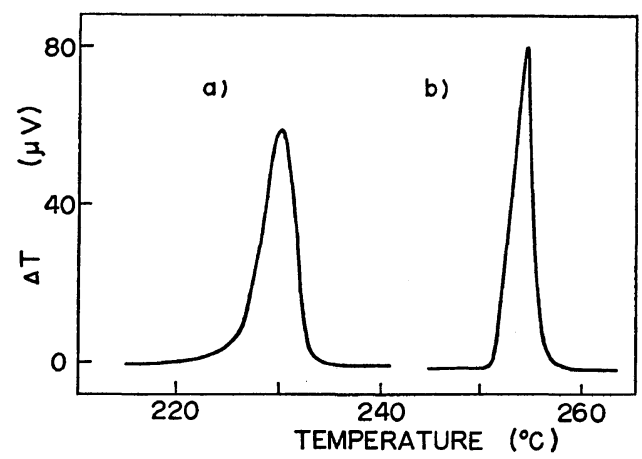

Figure 3. DTA traces of a) M3040 crystal (1.03 $\mathrm{mg})$ at 4995 bar and b) bismuth $(4.92 \mathrm{mg})$ at 5005 bar; heating rate, $6^{\circ} \mathrm{C} / \mathrm{min}$. 
Table II. Melting temperature of fully extended chain crystals of low molecular weight polyethylene fractions under pressure

M2230

\begin{tabular}{rr}
\hline $\boldsymbol{P}$, bar & $T_{\mathrm{m}},{ }^{\circ} \mathrm{C}$ \\
\hline 1 & 121.9 \\
305 & 130.5 \\
- & - \\
700 & 140.8 \\
1002 & 149.0 \\
1500 & 159.8 \\
2012 & 170.7 \\
2515 & 181.6 \\
3013 & 190.6 \\
3509 & 200.3 \\
4008 & 207.7 \\
4996 & 223.2 \\
\hline
\end{tabular}

M3040

\begin{tabular}{rr}
\hline$P$, bar & $T_{\mathrm{m}},{ }^{\circ} \mathrm{C}$ \\
\hline 1 & 126.6 \\
298 & 135.0 \\
498 & 140.3 \\
701 & 145.4 \\
996 & 152.9 \\
1504 & 164.0 \\
1995 & 175.1 \\
2501 & 184.8 \\
3011 & 194.6 \\
3500 & 203.4 \\
4000 & 211.9 \\
4995 & 227.6
\end{tabular}

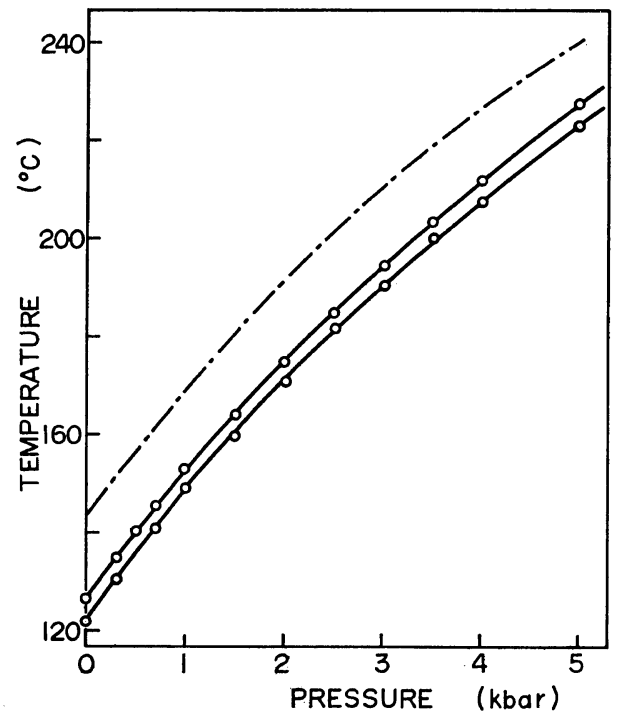

Figure 4. Melting curve of fully extended chain crystals of low molecular weight polyethylene fractions: solid line, (upper) M3040, (lower) M2230; dot-dashed line, pressure-crystallized sample (Davidson and Wunderlich ${ }^{10}$ ).

$$
\left(T_{\mathrm{m}} / T_{\mathrm{m} 0}\right)^{c}=\left(P-P_{0}\right) / a+1
$$

where $T_{\mathrm{m}}$ is the melting temperature at pressure $P, T_{\mathrm{m} 0}$ that at atmospheric pressure $P_{0}$, and $a$ and $c$ are constants that depend on each substance. The method of least squares fitting is described in an Appendix. The constants determined are tabulated in Table III. Attempts to fit the data to expressions of quadratic or cubic series in pressure led to larger variances than that obtained for the case of the Simon equation. The equation is applicable to the low molecular weight polyethylene studied as well as to $n$ paraffin. ${ }^{14,22}$

As shown in Table III, $a$ and $c$ are dependent on the molecular weight. The slopes $\left(\mathrm{d} T_{\mathrm{m}} / \mathrm{d} P\right)_{P}$ of the melting curves of both crystals, however, are identical to within experimental errors over the pressure range studied. Figure 4 clearly shows the agreement in the slope. The values of $\left(\mathrm{d} T_{\mathrm{m}} / \mathrm{d} P\right)_{P}$ were calculated from the Simon equation constants, and those at 1 and 5,000 bar are listed in Table III. The dot-dashed line in Figure 4 is the melting curve for pressure-crystallized polyethylene given by Davidson and Wunderlich. ${ }^{10}$ It was expressed by the quadratic equation. Up to about $3 \mathrm{kbar}$, its slope is in fair agreement with ours. However, extrapolation of their result gives a value of $\left(\mathrm{d} T_{\mathrm{m}} / \mathrm{d} P\right)_{P}$ that is lower by $3^{\circ} \mathrm{C} / \mathrm{kbar}$ than our result at 5 kbar. Although the present study is confined to extended-chain crystals of thin crystallite thickness, it seems that the slopes of the melting curve of extended-chain crystals having thick thickness are almost the same irrespective of the thickness. This suggests that the effect of superheating on the data of Davidson and Wunderlich is independent of pressure.

\section{DT $A$ and Melting Temperature of Folded-Chain Crystals under Pressure}

Figure 5 shows the DTA curves of M45000 folded-chain crystal under different pressures.

Table III. Constants of the Simon equation and $\left(\mathrm{d} T_{\mathrm{m}} / \mathrm{d} P\right)_{P}$ for polyethylene crystals

\begin{tabular}{lcccccc}
\hline \multirow{2}{*}{ Fraction } & $P_{\max }, \mathrm{kbar}$ & $T_{\mathrm{m} 0}, \mathrm{~K}$ & $a, \mathrm{kbar}$ & $c$ & \multicolumn{2}{c}{$\left(\mathrm{d} T_{\mathrm{m} / \mathrm{d} P)_{P}, \mathrm{~K} / \mathrm{kbar}}\right.$} \\
& & & & & at 1 bar & at $5 \mathrm{kbar}$ \\
\hline M2230 & 5 & 395.1 & $3.40 \pm 0.08$ & $3.95 \pm 0.07$ & $29.4 \pm 0.9$ & $15.0 \pm 0.4$ \\
M3040 & 5 & 399.8 & $3.62 \pm 0.04$ & $3.85 \pm 0.04$ & $28.7 \pm 0.4$ & $15.1 \pm 0.2$ \\
M45000 & 2.5 & 400.4 & $3.15 \pm 0.12$ & $4.22 \pm 0.13$ & $30.1 \pm 1.5$ & \\
\hline
\end{tabular}




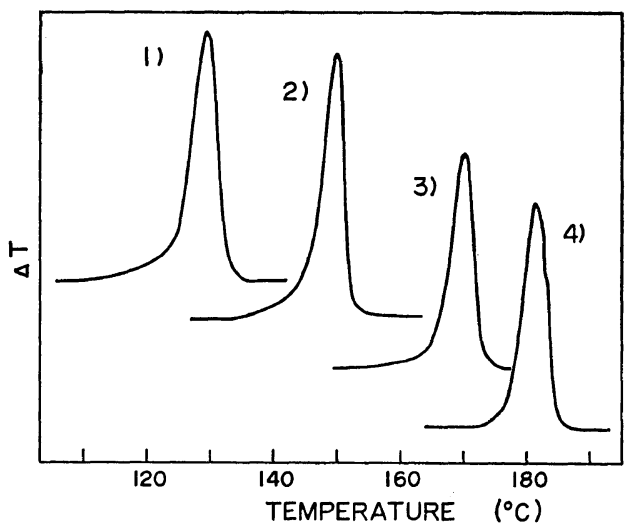

(a)

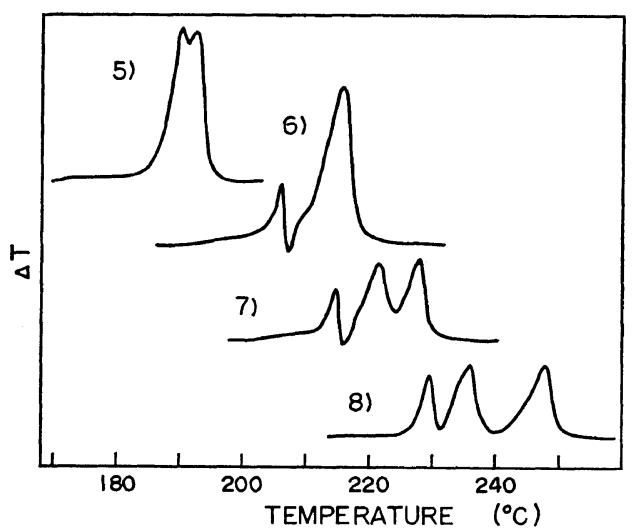

(b)

Figure 5. DTA traces of M45000 folded-chain polyethylene under different pressures: Heating rate, $6^{\circ} \mathrm{C} / \mathrm{min}$; sample size, about $1.0 \mathrm{mg}$ : (a) (1) 1 ; (2) 696; (3) 1492; (4) 1999 bar; (b) (5) 2480; (6) 3507 ; (7) 3996 ; (8) 5018 bar.

This crystal, having a lamellar thickness of $180 \AA$, melted without reorganization at ordinary pressure and its melting temperature could be given by the intersection temperature. ${ }^{23}$ The DTA curve at low pressure below $1.5 \mathrm{kbar}$ shows a sharp, single melting peak. With increase in pressure a shoulder appears, and then the peak becomes a doublet. A definite exothermic process is observed at $3.5 \mathrm{kbar}$. At pressures above 4 $\mathrm{kbar}$ three peaks are resolved. These findings can be interpreted as a process of partial melting followed by recrystallization ${ }^{24,25}$ goes on more rapidly and easily as pressure increases. They are similar to the features of DTA curves ob- tained at atmospheric pressure on solution-grown crystals: thick crystals gave single peak, whereas thin ones showed a multiple peak. ${ }^{23}$ If this interpretation is correct, the higher two peaks of the three can be assigned to the melting of crystallites with different degrees of perfection formed on the heating process. There is, however, a possibility that they correlate with an appearance of the high-pressure phase proposed by Bassett and Turner ${ }^{26,27}$ and by Takemura and coworkers. ${ }^{13}$ If this proposal is adopted, the second and third peaks may be assigned to the transition of crystallites formed in the heating process to the high-pressure phase and to its melting, respectively. Which interpretation is correct cannot be answered at present.

On the basis of the features seen in Figure 5, the intersection temperatures of the DTA peaks obtained at least at pressures below $2.5 \mathrm{kbar}$ may be taken as the melting temperature without significant error. With increase in pressure the difference between the two temperatures may become large.

The melting temperature at $5 \mathrm{kbar}$ was estimated from an annealing experiment. The temperature at which the original lamellar thickness begins to thicken can be defined as the melting temperature. ${ }^{28}$ As mentioned in the Experimental Section, the pressure vessel had a large heat capacity, so a long time was needed before it attained an annealing temperature $T_{\mathrm{a}}$. Therefore, an identical specimen was used to avoid any undesired effects before the attainment of $T_{\mathrm{a}}$. After an annealing at a $T_{\mathrm{a}}$ the crystallite thickness and the DTA melting were measured at atmospheric pressure. Then, the specimen was again annealed at a slightly higher $T_{\mathrm{a}}$. In Figure 6a, $L$ is plotted against $T_{\mathrm{a}}$. Because the shape of the DTA curve changed as $T_{\mathrm{a}}$ was increased, plots of both the intersection and the peak temperature against $T_{\mathrm{a}}$ are shown in Figure 6b. The annealing pressure for each point was 5,000 bar and controlled to within \pm 5 bar. An abrupt increase in $L$ is observed at a temperature in the region of $225^{\circ} \mathrm{C}$, whereas $L$ remains constant at lower $T_{\mathrm{a}}$. Although the DTA temperatures of both the intersection and the peak show gradual changes, the experimental points may fall, in each case, into two regions. A critical temperature is also observed at a temperature 

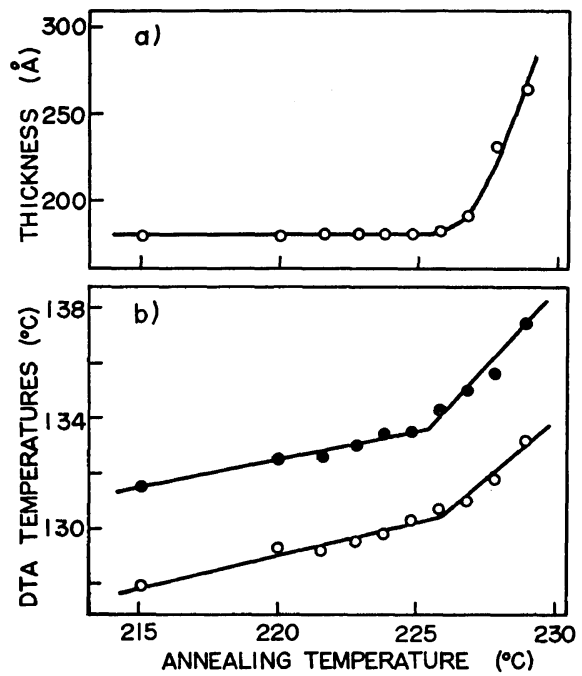

Figure 6. Change of a) lamellar thickness and b) DTA temperatures at 1 bar $(O$, the intersection; - the peak) of M45000 folded-chain polyethylene after annealing with successive increases in temperature.

near $225^{\circ} \mathrm{C}$. This critical temperature is taken as $225.5 \pm 0.5^{\circ} \mathrm{C}$ and can be regarded as the melting temperature of the M45000 crystal. Annealing experiments were also made on small pieces of the crystal coated by epoxy resin, just as in the high-pressure DTA, and resulted to similar relation between $T_{\mathrm{a}}$ and atmospheric DTA temperatures. The critical temperature was $225.0 \pm 0.5^{\circ} \mathrm{C}$ for annealing pressures of $4,940 \pm$ 15 bar. Both annealing experiments showed that the silicone oil used is inert to polyethylene under these experimental conditions. The melting temperature determined by the annealing experiments is about $1{ }^{\circ} \mathrm{C}$ lower than the corresponding high-pressure DTA intersection temperature. This finding indicates that the melting temperatures of the folded-chain crystal even at higher pressures can be measured approximately by means of DTA. The fact that the DTA temperatures increase at lower $T_{\mathrm{a}}$, whereas $L$ is constant, was observed also in the atmospheric annealing experiment and may be interpreted in terms of a stabilization of basal surface structures of the crystal by annealing.

The experimental data of the M45000 crystal are listed in Table IV and plotted in Figure 7. The intersection temperatures up to $2.5 \mathrm{kbar}$,
Table IV. Melting temperature ${ }^{a}$ of folded-chain crystals of high molecular weight polyethylene fraction under pressure

\begin{tabular}{rc}
$P$, bar & $T_{\mathrm{m}},{ }^{\circ} \mathrm{C}$ \\
\hline 1 & 127.2 \\
304 & 136.0 \\
500 & 141.3 \\
696 & 146.5 \\
1009 & 154.5 \\
1492 & 165.5 \\
1999 & 177.1 \\
2480 & 186.0 \\
2968 & $(194.4)$ \\
3507 & $(203.9)$ \\
3996 & $(211.8)$ \\
5018 & $(226.5)$ \\
5000 & $225.5^{\mathrm{b}}$ \\
\hline
\end{tabular}

a The temperatures, except ${ }^{b}$, are the DTA intersection temperatures. The parenthesized values may be slightly higher than the melting temperature. b Determined by the pressure annealing experiment.

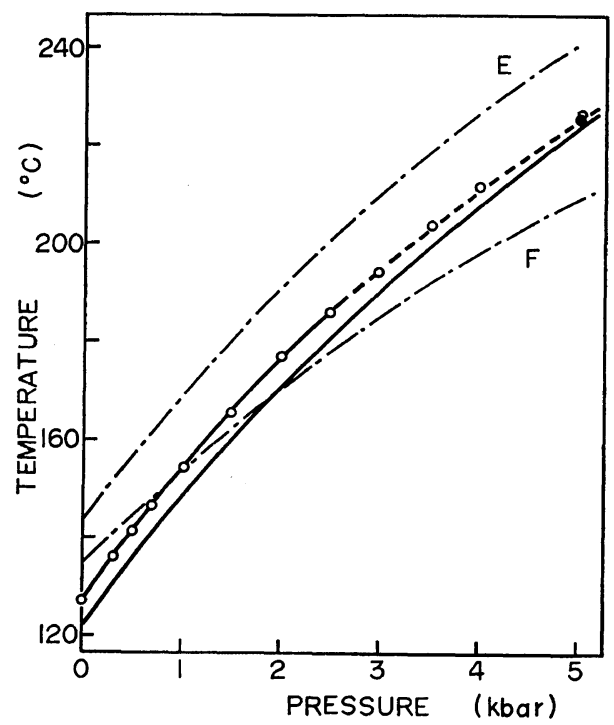

Figure 7. Melting curve of M45000 folded-chain polyethylene: (O) DTA intersection temperature; (-) determined by annealing; lower solid line, M2230; dot-dash lines, relation of Davidson and Wunderlich, ${ }^{10} \mathrm{E}$ for pressure-crystallized, and $\mathrm{F}$ for slowly cooled polyethylene.

taken as the melting temperatures, were fitted to the Simon equation. These constants are listed also in Table III, and the relation is rep- 
resented by a solid line through the points in Figure 7. An extrapolated broken line is constructed to pass through the point determined by the annealing experiment. The melting curve for the M45000 crystal below about $2 \mathrm{kbar}$ has almost the same slope as that for the M2230 crystal (lower solid line). As pressure increases the former approaches the latter. The dot-dashed lines, $E$ and $F$, are the melting curves for extended- and folded-chain crystals reported by Davidson and Wunderlich. ${ }^{10}$ The deviation between curve $F$ and our curve increases with pressure. Although their folded-chain crystals were not well-defined, such a marked discrepancy cannot be expected only from the difference in the detailed morphological nature between their crystals and ours. In connection with this, the effect of characteristics of lamellar crystallites on the slope $\left(\mathrm{d} T_{\mathrm{m}} / \mathrm{d} P\right)_{0}$ at atmospheric pressure will be discussed in the following paragraph. That the melting temperatures given by $F$ are lower at high pressures than those given by our relation seems partly to arise from an increased dissolution of nitrogen as a pressurizing gas into disordered surface layers of the crystal. This interpretation is supported by the finding of Calvert and Uhlmann ${ }^{29}$ that the exposure of samples to the pressurizing gas affects the crystallization process and the resulting morphologies.

They found, on the other hand, from the dependence of lamellar thickness on crystallization undercooling that the ratio of surface free energy to heat of fusion per unit volume at 5 $\mathrm{kbar}$ was about 5 times that at atmospheric pressure. They also stated that this result was in agreement with that obtained from the relation between the melting curves $E$ and $F$ : in this case the former was regarded as an equilibrium melting curve. Figure 7 clearly indicates that the depression of the melting temperature of the folded-chain crystals is not so large even at the high pressures they discussed. Their data obtained on the basis of crystallization kinetics seems to be in conflict with the thermodynamic data.

Slope of Melting Curve $\left(d T_{\mathrm{m}} / d P\right)_{0}$ of Lamellar Crystallites at Atmospheric Pressure

As shown in Figure 7 , our $\left(\mathrm{d} T_{\mathrm{m}} / \mathrm{d} P\right)_{0}$ for the folded-chain crystal is higher than that of Davidson and Wunderlich. ${ }^{10}$ Concerning this low value of $\left(\mathrm{d} T_{\mathrm{m}} / \mathrm{d} P\right)_{0}$ they stated that "the metastable folded-chain crystals are too far from equilibrium to be described by the ClausiusClapeyron equation." In order to examine whether this statement is correct or not we will discuss the slope for lamellar crystallites in terms of a two-phase model.

According to the model, lamellar crystallites are composed of a crystalline core and disordered surface layers, whose density is assumed to be identical with that of a supercooled liquid. A further assumption is that the mass crystallinity $\alpha_{\mathrm{m}}$ of the crystal remains unchanged up to its melting temperature $T_{\mathrm{m}}$. The Clausius-Clapeyron relation for this crystal is given by

$$
\left(\mathrm{d} T_{\mathrm{m}} / \mathrm{d} P\right)_{0}=T_{\mathrm{m}} \Delta V^{*} / \Delta H^{*}
$$

where $\Delta H^{*}$ is the heat of fusion per unit mass of the crystal, and $\Delta V^{*}$ the corresponding specific volume change on fusion. When $\left(\mathrm{d} T_{\mathrm{m}} / \mathrm{d} P\right)_{0}$ is expressed by the product of the slope $\left(\mathrm{d} T_{\mathrm{m}}{ }^{0} / \mathrm{d} P\right)_{0}$ for a hypothetically perfect crystal and a correction factor $F$, the following relation is obtained:

$$
F=\Delta v \alpha_{\mathrm{m}}\left(T_{\mathrm{m}} / T_{\mathrm{m}}{ }^{0}\right)\left(\Delta H^{0} / \Delta H^{*}\right)
$$

where the superscript 0 designates the perfect crystal, and $\Delta v$ is a correction factor arising from a temperature dependence of $\Delta V^{0}: \Delta v=$ $1-\left(1 / \Delta V^{0}\right)\left(\partial \Delta V^{0} / \partial T\right)\left(T_{\mathrm{m}}{ }^{0}-T_{\mathrm{m}}\right)$. We can rewrite eq 3 as

$$
F=\Delta v\left(1-2\left(\sigma-\sigma_{H}\right) / \alpha_{\mathrm{m}} \rho L \Delta H^{0}\right)
$$

using the relations

$$
T_{\mathrm{m}} / T_{\mathrm{m}}{ }^{0}=1-2 \sigma / \alpha_{\mathrm{m}} \rho L \Delta H^{0}
$$

and

$$
\left(\Delta H^{*} / \alpha_{\mathrm{m}}\right) / \Delta H^{0}=1-2 \sigma_{H} / \alpha_{\mathrm{m}} \rho L \Delta H^{0}
$$

where $\sigma$ and $\sigma_{H}$ are the surface free energy and enthalpy, respectively. The difference $\sigma-\sigma_{H}$ is approximately equal to $-T_{\mathrm{m}}^{0} \sigma_{S}$, in which $\sigma_{S}$ is the surface entropy. It should be noted that $\sigma$ for the low molecular weight extended-chain crystals involves a entropy term arising from a partial unpeeling, as discussed by Mandelkern. ${ }^{12,30}$

Table $\mathrm{V}$ lists $-T_{\mathrm{m}}{ }^{0} \sigma_{S}$ and $F$ for the crystals studied. The values of $\Delta v$ were calculated from extrapolated values of the unit subcell ${ }^{31}$ and the melt $^{32}$ of polyethylene up to the melting tem- 
Table V. Correction factors for the slopes of the melting curves at atmospheric pressure for polyethylene crystals

\begin{tabular}{lrrrr}
\hline Fraction & $\begin{array}{r}T_{\mathrm{m}}{ }^{0} \sigma_{S}, \\
\mathrm{erg} / \mathrm{cm}^{2}\end{array}$ & $F$ & \multicolumn{2}{c}{$\left(\mathrm{d} T_{\mathrm{m}} / \mathrm{d} P\right)_{0}, \mathrm{~K} / \mathrm{kbar}$} \\
\cline { 4 - 5 } M2230 & -10 & 0.95 & 32.0 & 29.4 \\
M3040 & 14 & 0.97 & 32.7 & 28.7 \\
M45000 & 87 & 1.01 & 34.0 & 30.1 \\
\hline
\end{tabular}

peratures, and the $\Delta v$ values are in the range 0.95 to 0.96 . Other values used are as follows: $T_{\mathrm{m}}{ }^{0}=418.5 \mathrm{~K}$ and $\Delta H^{0}=69.7 \mathrm{cal} / \mathrm{g} \cdot{ }^{33}$ Table $\mathrm{V}$ shows that, although $-T_{\mathrm{m}}{ }^{0} \sigma_{S}$ depends on the surface structures of the crystallites, the difference in $F$ is small. This is in agreement with our finding for $\left(\mathrm{d} T_{\mathrm{m}} / \mathrm{d} P\right)_{0}$, but not with that of Davidson and Wunderlich. ${ }^{10}$ It is expected that $F$ does not differ much from 1.0 for samples crystallized in the usual way. Our values of $\left(\mathrm{d} T_{\mathrm{m}} / \mathrm{d} P\right)_{0}$ are slightly lower than those calculated from $F$ and $\left(\mathrm{d} T_{\mathrm{m}}{ }^{0} / \mathrm{d} P\right)_{0}=33.8^{\circ} \mathrm{C} / \mathrm{kbar}$. This may be caused partly by the simplified assumption concerning the specific volume of the surface disordered layers.

Acknowledgment. The authors are particularly indebted to Professor T. Takemura of this department for his valuable guidance in the high pressure experiments and for many useful discussions. The authors also gratefully acknowledge the assistance of Messrs. T. Okudaira, J. Tabuchi, M. Yamato, and K. Maruta in preparing the molecular weight fractions and of $\mathrm{Mr}$. $\mathrm{M}$. Uchida in obtaining some of the data.

\section{APPENDIX}

The method for fitting the data to the Simon equation, eq 1 , was proposed by $\mathrm{Babb}^{14}$ on the assumption that $P$ was the only source of error. In DTA measurements, however, the determination of $T_{\mathrm{m}}$ leads to larger errors than that of $P$ does, so $P$ is assumed to be free from error.

Then, the object is to minimize the sum of squares of residuals

$$
\begin{aligned}
S & =\sum\left(T_{\mathrm{m} i}-T_{\mathrm{m} 0} x_{i}\right)^{2} \\
x_{i} & =\left(\left(P_{i}-P_{0}\right) / a+1\right)^{1 / c}
\end{aligned}
$$

by variation of $a$ and $c$, where the sum extends over all experimental points, $T_{\mathrm{m} i}$ and $P_{i}$. The most probable values, $a_{0}$, and $c_{0}$, of $a$ and $c$ can be solved approximately by linearization of eq A1. They are given by the following equations, which make use of their approximate values, $a^{\prime}$ and $c^{\prime}$ :

$$
\begin{aligned}
a_{0} & =a^{\prime}-([d d][b m]-[b d][d m]) / \Delta \\
c_{0} & =c^{\prime}-([b b][d m]-[b d][b m]) / \Delta \\
\Delta & =[b b][d d]-[b d]^{2}
\end{aligned}
$$

where the bracketed quantities represent the sum of the products of elements given as follows:

$$
\begin{aligned}
& b:-\left(T_{\mathrm{m} 0}\left(P_{i}-P_{0}\right) / c^{\prime} a^{\prime 2}\right) y_{i}{ }^{1 / c^{\prime}-1} \\
& d:-\left(T_{\mathrm{m} 0} / c^{\prime 2}\right) y_{i}{ }^{1 / c^{\prime}} \ln y_{i} \\
& m: T_{\mathrm{m} 0} y_{i}{ }^{1 / c^{\prime}}-T_{\mathrm{m} i} \\
& y_{i}=\left(P_{i}-P_{0}\right) / a^{\prime}+1
\end{aligned}
$$

In our cases $a_{0}$ and $c_{0}$ usually converged to final values with two or three trials.

The probable errors, $r_{a}$ and $r_{c}$, for $a_{0}$ and $c_{0}$ are given by

$$
\begin{aligned}
r_{a} & =0.6745\left([d d] \sigma^{2} / \Delta\right)^{1 / 2} \\
r_{c} & =0.6745\left([b b] \sigma^{2} / \Delta\right)^{1 / 2} \\
\sigma^{2} & =S /(n-2)
\end{aligned}
$$

where $n$ is the number of the experimental points.

\section{REFERENCES}

1. B. Wunderlich and T. Arakawa, J. Polym. Sci., Part A, 2, 3697 (1964).

2. B. Wunderlich and T. Davidson, ibid., Part $A$ 2, 7, 2043 (1969).

3. T. Davidson and B. Wunderlich, ibid., Part A2, 7, 2051 (1969).

4. S. Matsuoka, ibid., 57, 569 (1962).

5. K. H. Hellwege, W. Knappe, and P. Lehmann, Kolloid-Z. Z. Polym., 183, 110 (1962).

6. E. Baer and J. L. Kardos, J. Polym. Sci., Part A, 3, 2827 (1965).

7. R. A. Baltenas and L. A. Igonin, Dokl. Akad. Nauk SSSR, 163, 917 (1965).

8. F. E. Karaz and L. D. Jones, J. Phys. Chem., 71, 2234 (1967).

9. J. Osugi and K. Hara, Nippon Kagaku Zasshi (J. Chem. Soc. Japan, Pure Chem. Sect.), 88, 33 (1967).

10. T. Davidson and B. Wunderlich, J. Polym. Sci., Part A-2, 7, 377 (1969).

11. R. Chiang and P. J. Flory, J. Amer. Chem. Soc., 83, 2857 (1961). 
12. J. G. Fatou and L. Mandelkern, J. Phys. Chem., 69, 417 (1965).

13. M. Yasuniwa, C. Nakafuku, and T. Takemura, Polymer J., 4, 526 (1973).

14. S. E. Babb, Jr., Rev. Mod. Phys., 35, 400 (1963).

15. P. W. Bridgman, Phys. Rev., 6, 1 (1915).

16. S. E. Babb, Jr., "The Mechanical Behavior of Materials under Pressure," H. L. D. Pugh, Ed., Elsevier, New York, N.Y., 1970, Chap. 3.

17. H. Kojima and K. Yamaguchi, Kobunshi Kagaku (Chem. High Polymers), 19, 715 (1962).

18. R. Chiang, J. Phys. Chem., 69, 1645 (1965).

19. K. Takamizawa and M. Hashiguchi, unpublished work.

20. R. B. Prime, B. Wunderlich, and L. Melillo, $J$. Polym. Sci., Part A-2, 7, 2091 (1969).

21. M. Jaffe and B. Wunderlich, "Thermal Analysis", Vol. 1, R. F. Schwenker, Jr. and P. D. Garn, Ed., Academic Press, New York, N.Y., 1969, p 387.
22. R. R. Nelson, W. Webb, and J.A. Dixon, J. Chem. Phys., 33, 1756 (1960).

23. K. Takamizawa, Y. Fukahori, and Y. Urabe, Makromol. Chem., 128, 236 (1969).

24. L. Mandelkern and A. L. Allou, Jr., J. Polym. Sci., Part B, 4, 447 (1966).

25. T. Kawai, Kolloid-Z. Z. Polym., 229, 116 (1969).

26. D. C. Bassett and B. Turner, Nature Phys. Sci., 240, 146 (1972).

27. D. C. Bassett and B. Turner, Phil. Mag., 29, 925 (1974).

28. L. Mandelkern, R. K. Sharma, and J. F. Jackson, Macromolecules, 2, 644 (1969).

29. P. D. Calvert and D. R. Uhlmann, J. Polym. Sci., Part A-2, 10, 1811 (1972).

30. L. Mandelkern, ibid., Part C, 15, 129 (1966).

31. P. R. Swan, ibid., 42, 525 (1960).

32. R. Chiang and P. J. Flory, J. Amer. Chem. Soc., 83, 2857 (1961).

33. P. J. Flory and A. Vrij, ibid., 85, 3548 (1963). 